\title{
COMPARING WATER VAPOR MIXING RATIO PROFILES AND CLOUD VERTICAL STRUCTURE FROM MULTIWAVELENGTH RAMAN LIDAR RETRIEVALS AND RADIOSOUNDING MEASUREMENTS
}

\author{
Montserrat Costa-Surós ${ }^{1 *}$, Iwona S.Stachlewska ${ }^{1}$, Krzysztof Markowicz ${ }^{1}$ \\ ${ }^{1}$ Institute of Geophysics, Faculty of Physics, University of Warsaw, Warsaw 02-093, Poland, \\ *Email:montsecs@igf.fuw.edu.pl
}

\begin{abstract}
A study of comparison of water vapor mixing ratio profiles, relative humidity profiles, and cloud vertical structures using two different instruments, a multiwavelength Aerosol-Depolarization-Raman lidar and radiosoundings, is presented. The observations were taken by the lidar located in Warsaw center and the radiosoundings located about $30 \mathrm{~km}$ to the North in Legionowo (Poland). We compared the ground-based remote sensing technology with in-situ method in order to improve knowledge about water content thought the atmosphere and cloud formation. The method used for retrieving the cloud vertical structure can be improved comparing the radiosonde results with the lidar observations, which show promising results.
\end{abstract}

\section{INTRODUCTION}

Clouds are key factor that rule climate. Improving methods for automatic and continuous description of clouds has a huge importance in order to determine the role of clouds in climate and their contribution to climate change [1]. The water vapor mixing ratio (WVMR), the relative humidity (RH) and the cloud vertical structure (CVS) in the atmosphere are important characteristics for describing the impact that clouds have in the atmosphere.

In the past, researchers undertook the approach for retrieval cloud layer structures only by using radiosounding (RS) data $[2,3]$. There is ongoing work being done to improve these methods and compare them with the most advanced groundbased remote-sensing technologies, such as the Atmospheric Radiation Measurement (ARM) Program value added product, the Active Remote Sensing of Clouds (ARSCL), as well as with satellite data [4]. In this work the comparison was done in order to find a better approximation to the CVS profile, and to reveal the strengths and weaknesses of both ground-based instruments and in-situ radiosoundings. Now, the present study aim is to make similar comparisons between radiosounding methods and advanced multiwavelength lidar measurements in Poland. The idea is to see if the results obtained with ARSCL data product (which is a combination of measurements taken with cloud radar, micro-pulse lidar, and ceilometer) are comparable with those obtained with measurements taken by a multiwavelength Aerosol-Depolarization-Raman (ADR) lidar. Moreover, apart from CVS comparison, the WVMR and RH profiles retrieved from the RS are also compared, since the multiwavelength lidar provide profiles in Raman channel for water.

\section{METHODOLOGY}

The lidar measurements were taken in the Radiative Transfer Laboratory (RT-Lab) of the Institute of Geophysics, Faculty of Physics, University of Warsaw (Poland). The RT-Lab site located at central Warsaw $\left(52.21^{\circ}, \mathrm{N} 20.98^{\circ} \mathrm{E}\right.$, $96 \mathrm{~m}$ asl) joined the EARLINET [5] in 2015, contributing to the network activities with the 8channel $(2 \alpha+3 \beta+2 \delta+\mathrm{VW})$ ADR lidar, that is a NeXT generation Polly XT system developed in a scientific cooperation with TROPOS, Germany [6]. Its detection channels are at 1064, 532 and $355 \mathrm{~nm}$ (elastic), at 607 and $387 \mathrm{~nm}$ (vibrational Raman for $\mathrm{N}_{2}$ ), 407nm (Raman channel for $\mathrm{H}_{2} \mathrm{O}$ ), and 532 and $355 \mathrm{~nm}$ (elastic cross channels), using photon counting detection for all channels. Moreover, RT-Lab is part of the Poland AOD network (http://www.polandaod.pl).

The radiosoundings were launched in Legionowo station, which is the nearest radio sounding station (code: 12374), located about $30 \mathrm{~km}$ to the North from the lidar at RT-Lab, and which frequency of radio sounding launches is $12 \mathrm{~h}$.

For the study we focused on one hand on the retrieval of WVMR and RH, and on the other, on 
the CVS. The main idea of our retrieval scheme is given below.

\subsection{Water vapor mixing ratio and relative humidity}

The mixing ratio of water vapor to dry air is obtained from nighttime observations. The available lidar wavelength for water vapor detection is not in the solar-blind region and thus the daytime measurements are roughly affected by background light noise. The WVMR profile $(m(z))$ is obtained from the measurement of the watervapor to the reference signal ratio, where the reference gas is nitrogen [7] (eq. 1).

$$
m(z)=K_{m} \frac{P_{\lambda_{H, o}}(z)}{P_{\lambda_{\text {Ref }}}(z)} \times \frac{\exp \left\{-\int_{0}^{z}\left[\alpha_{\lambda_{\text {eqf }}}^{\text {aer }}(\xi)+\alpha_{\lambda_{\text {Ref }}}^{\text {mol }}(\xi)\right] d \xi\right\}}{\exp \left\{-\int_{0}^{2}\left[\alpha_{\lambda_{t, 0}}^{\text {aer }}(\xi)+\alpha_{\lambda_{t, o}}^{\text {mol }}(\xi)\right] d \xi\right\}}
$$

The $\mathrm{P}_{\lambda \mathrm{H} 2 \mathrm{O}}(\mathrm{z})$ and $\mathrm{P}_{\lambda \mathrm{Ref}}(\mathrm{z})$ are the return signals from distance $\mathrm{Z}$ at the laser wavelength for the water-vapor (at $407 \mathrm{~nm}$ ) and the Raman reference wavelength (at $387 \mathrm{~nm}$, a vibrational Raman channel for $\mathrm{N}_{2}$ ). The $\alpha^{\text {aer }}$ and $\alpha^{\text {mol }}$ describe the extinction of light (either in the water-vapor or the reference wavelength), by aerosol particles and air molecules. Extinction coefficients $(\alpha)$ are derived from the Raman signal profile of the reference gas (eq. 2) [7].

$$
\alpha_{\lambda_{0}}^{\text {aer }}(z)=\frac{d / d z\left[\ln \left[N_{\text {Ref }}(z) / P_{\lambda_{\text {Ref }}}(z) z^{2}\right]\right)-\alpha_{\lambda_{0}}^{\text {mol }}(z)-\alpha_{\lambda_{\lambda_{e f}}^{\text {mol }}(z)}}{1+\left(\lambda_{0} / \lambda_{\text {Ref }}\right)^{k}}
$$

The $\mathrm{N}_{\text {Ref }}(\mathrm{z})$ is the molecular number density of the reference gas. The $\lambda^{-k}$ describes the wavelength dependence of particle scattering; $k=1$ is used except for ice clouds for which we set $\mathrm{k}=0$.

The overall system constant $\mathrm{K}_{\mathrm{m}}=\mathrm{K}_{\lambda \mathrm{Ref}} / \mathrm{K}_{\lambda \mathrm{H} 2 \mathrm{O}}$ can in principle be deduced from the known Raman cross sections and the measured properties of the detector used. In practice it was determined from a comparison of the lidar measurement with critically evaluated data from a radiosonde ascent [7].

Furthermore, relative humidity profiles are obtained as the ratio between the MWVR (from RS and lidar respectively) and the saturation vapor pressure (calculated with Clasius-Clapeyron equations).

\subsection{Cloud vertical structure}

The CVS is determined from RS using the method by [8] conveniently modified as explained in [4], hereafter entitled as method COS14. Specifically, the method for determining cloud tops and bases is based in $\mathrm{RH}$ thresholds applied to the RS profile. As a first step, the RH with respect to liquid water is converted to $\mathrm{RH}$ with respect to ice when the temperature is below $0^{\circ} \mathrm{C}$. Then, moist layers are identified by applying some conditions, which are related to a minimum $\mathrm{RH}$ threshold (min-RH) and to a minimum thickness $(400 \mathrm{~m})$. Subsequently, moist layers are defined as cloud layers through some additional steps: (a) if the maximum RH within the layer is greater than the corresponding maximum RH threshold (max-RH) for the base of this moist layer, (b) the base of cloud layers is set at least at $280 \mathrm{~m}$ above ground level, and (c) two contiguous layers are considered as a single-layer cloud if the distance between these two layers is less than $300 \mathrm{~m}$ or the minimum RH within this distance is greater than the corresponding inter-RH threshold value. Note that instead of single-humidity thresholds to define a cloud as in earlier works [2, 3], this method is based on altitude-dependent thresholds, which vary between $70 \%$ and $95 \%$ depending on the specific threshold (min-RH, inter-RH, and max-RH) and on the altitude (greater values of humidity thresholds correspond to lower atmospheric layers) $[4,8]$.

First approximation to the CVS from multiwavelength lidar is taken from visual inspection of the plotted signals at $1064 \mathrm{~nm}$. Then, to determine CVS more accurately, thresholds are applied to the profiles of backscatter coefficients (at 355, 532 and $1064 \mathrm{~nm}$; eq. 3), extinction coefficients (at 355 and $532 \mathrm{~nm}$; eq. 2), as well as depolarization ratios (at 355 and 532; which are determined by the ratio between the cross polarized signal to the total signal).

$$
\begin{gathered}
\beta_{\lambda_{0}}^{\text {aer }}(z)=\left[\beta_{\lambda_{0}}^{\text {aer }}\left(z_{0}\right)+\beta_{\lambda_{0}}^{\text {mol }}\left(z_{0}\right)\right] \\
x \frac{P_{\lambda_{\text {Ref }}}\left(z_{0}\right) P_{\lambda_{0}}(z) N_{\text {Ref }}(z)}{P_{\lambda_{0}}\left(z_{0}\right) P_{\lambda_{\text {Ref }}}(z) N_{R e f}\left(z_{0}\right)} \\
x \frac{\exp \left\{-\int_{z_{0}}^{z}\left[\alpha_{\lambda_{\text {Ref }}}^{\text {aer }}(\xi)+\alpha_{\lambda_{\text {Ref }}}^{\text {mol }}(\xi)\right] d \xi\right\}}{\exp \left\{-\int_{z_{0}}^{z}\left[\alpha_{\lambda_{0}}^{\text {aer }}(\xi)+\alpha_{\lambda_{0}}^{\text {mol }}(\xi)\right] d \xi\right\}}-\beta_{\lambda_{0}}^{\text {mol }}(z)
\end{gathered}
$$




\section{RESULTS}

Examples of lidar signals are shown in Figs. 1a and $b$. Both observations are at $1064 \mathrm{~nm}$ over Warsaw since we want to see cloud particles. Fig. 1a shows lidar range-corrected signals during 29/07/14 from 18 to $24 \mathrm{~h}$ UTC, where aerosol complex structures in boundary layer are visible from the overlap level up to $2500 \mathrm{~m}$ approximately, whereas a thinner aerosol layer is discernible at $4000 \mathrm{~m}$. Fig. 1b shows rangecorrected signals on $30 / 07 / 14$ from 12 to $17 \mathrm{~h}$ UTC. This period was partially cloudy: discontinuous cloud layer with the base at 1000 $\mathrm{m}$, and other higher clouds between 2000 and $4000 \mathrm{~m}$ are distinguished. Note that cloud signatures are clearly distinguished from aerosol layers since the signal behind their bases are very attenuated.

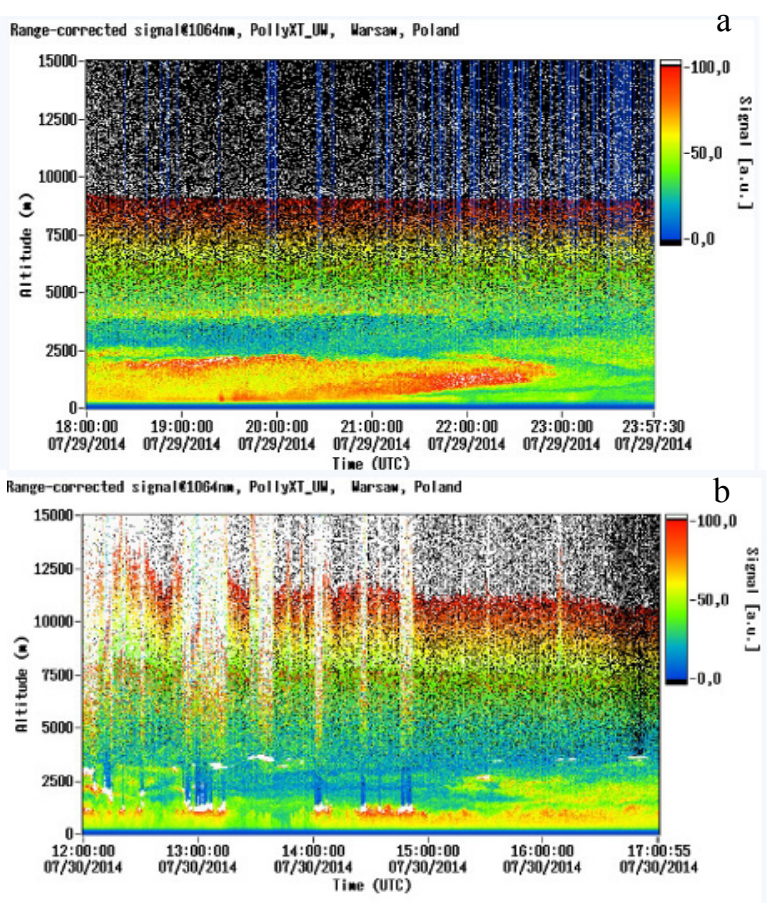

Fig. 1. a) Lidar signals at $1064 \mathrm{~nm}$ over Warsaw on $29 / 07 / 14$ from 18 to $24 \mathrm{~h}$, and b) on 30/07/14 from 12 to $17 \mathrm{~h}$ UTC. These figures are available at http://polly.rsd.tropos.de/.

\subsection{Water vapor mixing ratio}

WVMR profile was calculated from Raman multiwavelength lidar signals over RT-Lab (Warsaw) from 23 to 24 on 29/07/14. According to lidar range corrected signals inspection there were no clouds during this period (Fig. 1a). Overall system constant $\left(\mathrm{K}_{\mathrm{m}}\right)$ has been determined as 5. In Fig. 2a the MWVR lidar profile is plotted along with the MWVR profile obtained by the RS. The two profiles agree well from the overlap level $(540 \mathrm{~m})$ to $3 \mathrm{~km}$, and from 4.6 to $8 \mathrm{~km}$, although at higher heights the MWVR profile obtained by the lidar become noisier.

In Fig. $2 b$ the RH from 3 sources is plotted. The first one is directly taken from the RS over Legionowo on 30/07/14 00UTC, secondly the RH derived from the MWVR from the same RS, and finally the RH derived from multiwavelength lidar signals from 23 to $24 \mathrm{~h}$ UTC on $29 / 07 / 14$ over central Warsaw. The figure shows good agreement between the RH calculated from lidar signals with the RH calculated from the RS up to $3 \mathrm{~km}$, and between 4.3 and $6 \mathrm{~km}$. The differences found between 3 to $4.3 \mathrm{~km}$ and above $6 \mathrm{~km}$ could be due to the distance between the lidar site and the RS launching station, which is about $30 \mathrm{~km}$.
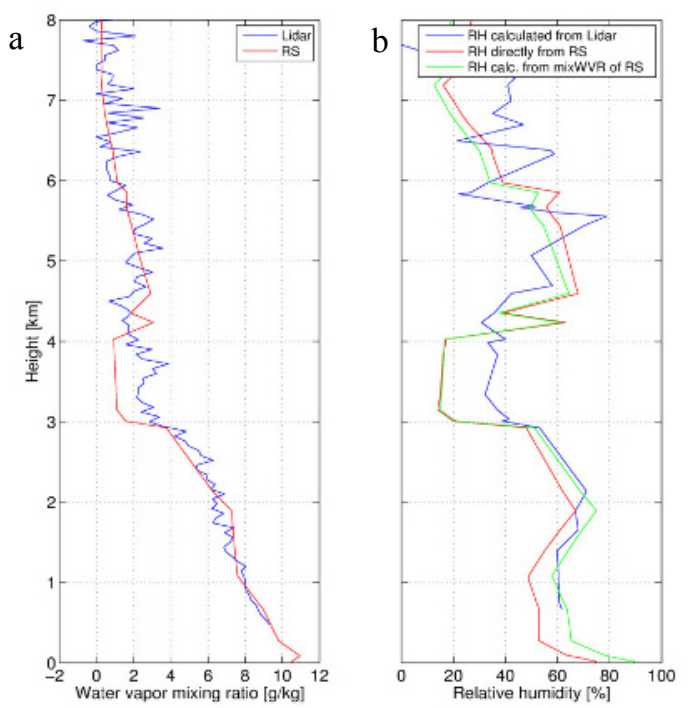

Fig. 2. a) MRWV to dry air profile from RS (in red), derived from Raman multiwavelength lidar signals (in blue); b) RH humidity profile obtained directly from RS (in red), derived from the WVMR from the RS (in green) and derived from Raman lidar signals (in blue). RS launched on 30/07/14 at 00UTC over Legionowo and lidar signals evaluated from 23 to 24 on $29 / 07 / 14$ over RT-Lab (Warsaw).

\subsection{Cloud vertical structure}

The comparison between the CVS from lidar signals and from the COS14 RS methodology [4] has been made for two different RS launchings. The first RS evaluated with COS14 method was on 30/07/14 at 00UTC and it did not reveal any 
cloud layer, which agrees with the visual inspection of the IR lidar signals (Fig. 1a).

The second RS evaluated is on 30/07/14 at 12UTC and it reveals a low level cloud layer (from $1.3 \mathrm{~km}$ to almost $3 \mathrm{~km}$ ) (Fig. 4 right), which agrees with the three layers seen on lidar signals

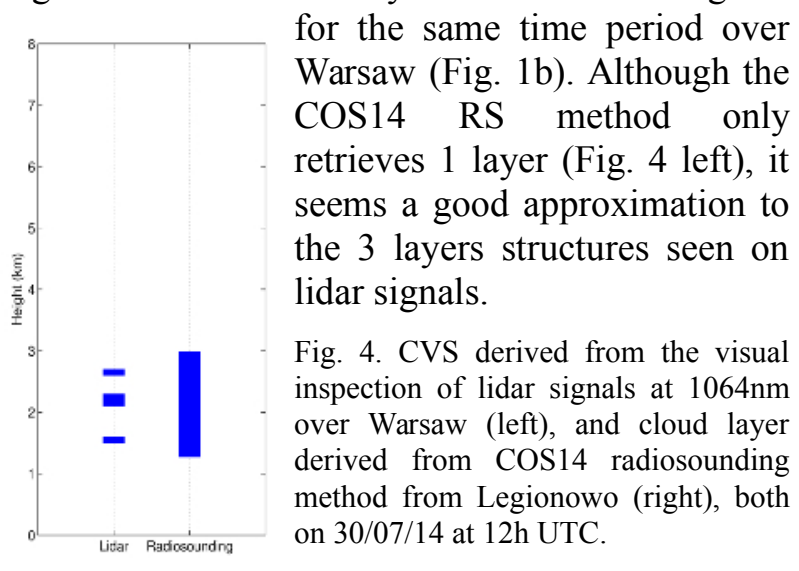

\section{CONCLUSIONS}

A comparison of the WVMR and RH between multiwavelength ground-based lidar (from 23 to $24 \mathrm{~h}$ on 29/07/14) based on Warsaw, and RS measurement (at 00h UTC on 30/07/14) launched in Legionowo, were retrieved up to $8 \mathrm{~km}$ successfully, and revealed a good agreement between the two methodologies at most heights, although the WVMR lidar derived showed noise. The differences in some parts of the WVMR and $\mathrm{RH}$ profiles could be due to geographical distance between the instruments. The comparison between CVS derived from visual inspection of groundbased multiwavelength ADR lidar and RS for two study cases produce good agreement. Despite on the second case, COS14 method only retrieves 1 cloud layer where the lidar derived 3 , the cloudy height range is good determined by the lidar.

Combining lidar measurements and their retrievals with other technologies, such as RS, is very important in order to get a better knowledge about water content thought the atmosphere and CVS. Such studies have potential to improve methods for automatic and continuous description of clouds [4] and will very useful to provide better inputs for modelers. In future, more comparisons will be performed for other case studies since it will be very useful for testing and eventually improving RS methods. Moreover, comparing RS methods retrievals with different multiwavelength systems operating around the world opens a huge range of possibilities.

\section{ACKNOWLEDGEMENT}

Part of the research was done within the SONATA BIS Project "Integrated study of climate processes involving absorbing aerosols" funded by $\mathrm{NCN}$, Poland (Grant No. 2012/05/E/ST10/01578).

The lidar development was financed by FNITP, Poland (Grant No.519/FNITP/115/2010).

\section{REFERENCES}

[1] Boucher, O., Randall, D., et al., 2013: Clouds and Aerosols. In: Climate Change 2013: The Phisical Science Basis. IPCC, 571-657.

[2] Wang, J., \& Rossow, W., 1995: Determination of Cloud Vertical Structure from Upper-Air Observations. J. Appl. Meteorol., 34(10), 22432258.

[3] Poore, K., Wang, J., \& Rossow, W., 1995: Cloud Layer Thicknesses from a Combination of Surface and Upper-Air Observations. J. Clim., 8(3), 550-568.

[4] Costa-Surós, M., Calbó, J., González, J. A., Long, C. N., 2014: Comparing the cloud vertical structure derived from several methods based on radiosonde profiles and ground-based remote sensing measurements. Atmos. Meas. Tech., 7(8), 2757-2773.

[5] Pappalardo, G., et al., 2014: EARLINET towards an advanced sustainable European aerosol lidar network, Atmos. Meas. Tech., 7, 2389-2409.

[6] Althausen, D., et al., 2009: Portable Raman Lidar PollyXT for Automated Profiling of Aerosol Backscatter, Extinction, and Depolarization. $J$. Atmos. Oceanic Technol., 47, 2366-2378.

[7] Ansmann, A., Riebesell, et al., 1992: Combined Raman Elastic-Backscatter LIDAR for Vertical Profiling of Moisture, Aerosol Extinction, Backscatter, and LIDAR Ratio, Applied Physics $B, \mathbf{5 5}, 18-28$.

[8] Zhang, J., et al., 2010: Analysis of cloud layer structure in Shouxian, China using RS92 radiosonde aided by $95 \mathrm{GHz}$ cloud radar. $J$. Geophys. Res., 115, 1-13. 